\title{
Health risks of adults in Hong Kong related to inhalation of particle- bound heavy metal(loid)s
}

\author{
Xiaocui Chen ${ }^{1,4} \mathbb{D} \cdot$ Tony J. Ward $^{2} \cdot$ Chinmoy Sarkar $^{1} \cdot$ Kin-Fai Ho $^{3} \cdot$ Chris Webster $^{1}$
}

Received: 11 March 2021 / Accepted: 18 October 2021 / Published online: 1 January 2022

(C) The Author(s) 2021

\begin{abstract}
Heterogeneity between ambient and personal exposure to heavy metals has been documented. However, few studies have investigated potential health risks posed by inhalational exposure to airborne heavy metal(loid)s at the individual level. A total of 404 personal fine particles $\left(\mathrm{PM}_{2.5}\right)$ samples were collected from 61 adult residents (aged 18-63 years) in Hong Kong during 2014-2015. Heavy metal(loid)s were analyzed using energy dispersive X-ray fluorescence. Among the analyzed heavy metal(loid)s, zinc ( $\mathrm{Zn}$ ) was the most abundant component in personal $\mathrm{PM}_{2.5}$, followed by lead $(\mathrm{Pb})$, copper $(\mathrm{Cu})$, and vanadium $(\mathrm{V})$; cobalt $(\mathrm{Co})$ and cadmium $(\mathrm{Cd})$ were not detectable. Health risks of personal exposure to heavy metal(loid) $\mathrm{s}$ via inhalation were assessed for adults, including non-cancer risks that were characterized by hazard quotient (HQ) and hazard index (HI). The results indicated that non-cancer risks of heavy metal(loid)s were attributable to $\mathrm{Cu}$, with a $95^{\text {th }} \mathrm{HQ}$ value $>1$. Arsenic (As) and hexavalent chromium [Cr (VI)] were also significant contributors to inhalation cancer risks $(>$ $1 \times 10^{-6}$ ) for the adult participants. Finally, we employed a Monte Carlo simulation to evaluate the uncertainty associated with health risk assessment. The mean and median upper-bound lifetime cancer risk associated with inhalation exposure to carcinogenic heavy metal(loid)s exceeded the acceptable level $\left(1 \times 10^{-6}\right)$ for adults. Traffic emission (including non-tailpipe exhaust), shipping emission, and regional pollution were significant sources of heavy metals. These findings suggest that emission controls targeting local vehicles and vessels should be given priority in Hong Kong.
\end{abstract}

Keywords Individual exposure $\cdot$ Toxic metals $\cdot$ Source identification $\cdot$ Cancer risk assessment $\cdot$ Monte Carlo simulation

\section{Introduction}

Exposure to heavy metal contaminants in various environmental media has raised concerns about the adverse impacts on human health (Silvera and Rohan 2007). Heavy metals

Xiaocui Chen

chenxcui@hku.hk

$\triangle$ Kin-Fai Ho

kfho@cuhk.edu.hk

1 Healthy High Density Cities Lab, HKUrbanLab, The University of Hong Kong, Hong Kong Special Administrative Region, Hong Kong, China

2 School of Public and Community Health Sciences, University of Montana, Missoula, MT, USA

3 The Jockey Club School of Public Health and Primary Care, The Chinese University of Hong Kong, Hong Kong Special Administrative Region, Hong Kong, China

4 Shenzhen Institute of Research and Innovation, The University of Hong Kong, Shenzhen, China tend to be bio-accumulated and attract more attention as they aggravate many health problems following prolonged exposure (Cao et al. 2016). Although accounting for a small fraction of fine particle $\left(\mathrm{PM}_{2.5}\right)$ mass, adverse health effects of exposure to heavy metal(loid)s-including nickel (Ni), chromium $(\mathrm{Cr})$, cobalt $(\mathrm{Co})$, and cadmium $(\mathrm{Cd})$, arsenic (As) - have been well documented in the literature (Huang et al. 2018; Wong et al. 2015). In particular, inhalational exposures to particle-bound metal(loid)s poses health threats to the human respiratory system, brain, and kidney dysfunction, and even causes cancer (Goldhaber 2003; Silvera and Rohan 2007). Past studies indicate that toxic metals in $\mathrm{PM}_{2.5}$ originate from various sources, and these emission sources are characterized by distinct metal components in urban areas (Jiang et al. 2014; Liu et al. 2020; Shi et al. 2011). Positive matrix factorization (PMF) and principal component analysis (PCA) are the most commonly utilized source identification and apportionment approaches. Duan and Tan (2013) indicated coal burning, iron and steel industry, and vehicle emissions were primary sources of heavy metal(loid) 
s [e.g., Cr, Ni, As, vanadium (V), manganese (Mn), copper $(\mathrm{Cu})$, zinc $(\mathrm{Zn})$, lead $(\mathrm{Pb})]$ in China.

Previous results revealed that measurements from ambient monitoring sites might not be sufficient to represent daily personal exposure to air pollutants (Richmond-Bryant and Long 2020). Jahn et al. (2013) determined that people spend most of their time indoors $(\sim 85 \%)$ in urban areas, with exposure to air pollution occurring from both indoor and ambient sources. There are several factors to consider in assessing personal exposure to air pollutants, including exposure to indoor-generated air pollutants (e.g., from cooking, cleaning activities, and incense burning), time spent outdoors, and personal activities (e.g., in public transport) (Lei et al. 2020; Morawska et al. 2013). As noted in Fan et al. (2018) and Chen et al. (2020b), these exposure studies revealed higher particle bioreactivity and adverse health effects in personal exposure than ambient air.

Health risks of heavy metals in urban soils (Luo et al. 2011), e-waste recycling (Lau et al. 2014), and indoor dust (Shi and Wang 2020) via different exposure routes (e.g., dermal contact, ingestion) have been assessed. Health risks associated with inhalation exposure to heavy metals in indoor and ambient air have also been reported (Hieu and Lee 2010; Huang et al. 2014). Some studies demonstrated higher exposure concentrations of heavy metals in ambient air compared to urban soil, with health risks exceeding acceptable levels $\left(1 \times 10^{-6}\right)$ (Hu et al. 2012).

Inhalation is a significant route for human exposure to metals in the atmosphere (U.S. EPA 2009). For example, Cao et al. (2016) indicated that inhalation exposure to heavy metals (e.g., Cr) (e.g., 43.8\%) along with exposure due to ingestion (e.g., 56.2\%) posed significant health risks to children in China. To further characterize inhalation exposure, personalized exposure assessment is considered a promising approach for human health studies (Morawska et al. 2013; Weis et al. 2005). Research efforts have been expanded to investigate the health risks of personal exposure to hazardous air pollutants, including volatile organic compounds (VOCs) (Zhou et al. 2011), polycyclic aromatic hydrocarbon compounds (PAHs) (Han et al. 2019), and heavy metals (iron, V, Ni, Cr, Cu, Zn) (Mao et al. 2020). In Hong Kong, many research efforts have been devoted to investigating the health risks of heavy metal(loid)s in soil and water (Lau et al. 2014; Man et al. 2010). Nonetheless, limited studies have focused on the potential health risks of personal exposure to airborne heavy metals at an individual level. A complete understanding of the emission sources and inhalation health risks of heavy metals in personal $\mathrm{PM}_{2.5}$ is vital to guide the development and implementation of interventional regulatory policies that improve air quality and protect individual and public health.

We conducted personal $\mathrm{PM}_{2.5}$ monitoring in adult Hong Kong residents during two sampling sessions. This study aims to (1) investigate exposure concentrations of heavy metals in personal $\mathrm{PM}_{2.5}$ exposure among adult residents, (2) explore the sources that contribute to heavy metals in personal $\mathrm{PM}_{2.5}$ exposure, and (3) evaluate potential non-cancer and cancer health risks of heavy metal(loid)s exposure via inhalation for adults. In addition, a Monte Carlo simulation was employed to assess the uncertainty associated with cancer risk assessment.

\section{Materials and methods}

\section{Study area description}

The Hong Kong Special Administrative Region, China, consists of eighteen districts (Fig. 1) characterized by a high population density, heavy traffic loads on its roads and streets, and surrounded by high-rise buildings. According to the 2016 census, the Hong Kong population has reached 7.34 million (Hong Kong Census and Statistics Department 2016). This includes $\sim 5$ million adults (between 20 and 64 years of age), accounting for $68.2 \%$ of the total Hong Kong population. Wong et al. $(2015,2020)$ indicated indoor and outdoor air pollution were significant risk factors related to head, heart, and human respiratory tract diseases (e.g., chronic obstructive pulmonary disease, lower respiratory infection, lung cancer) in the Hong Kong population (Wong et al. 2015, 2020). The present study assessed the health risks of personal exposure to heavy metals in adult residents of Hong Kong, a crucial life stage for the onset and progression of various diseases. The study was conducted over the period from April 2014 to June 2015; the temperature, relative humidity, precipitation, and wind speed were 24.1 $\pm 4.7{ }^{\circ} \mathrm{C}, 79.8 \pm 11.1 \%, 0-122.1 \mathrm{~mm}$, and $2.9 \pm 1.7 \mathrm{~m} / \mathrm{s}$, respectively (Table 1). Seasonal variation in ambient $\mathrm{PM}_{2.5}$ (and metal component) concentrations have been reported in another publication (Chen et al. 2019a); higher ambient concentrations were reported during the winter monsoon period than the summer monsoon in Hong Kong.

\section{Study subjects and exposure survey}

As part of this project, 61 adult subjects residing in different districts of Hong Kong were recruited for personal $\mathrm{PM}_{2.5}$ monitoring employing a non-probability sampling approach. All study subjects were non-smokers and free from chronic diseases. Detailed information regarding study design and methodology was presented in previous publications (Chen et al. 2019a, 2018). In brief, this study consists of two sampling sessions (Table 1). Of the 61 local participants, 48 subjects completed a 


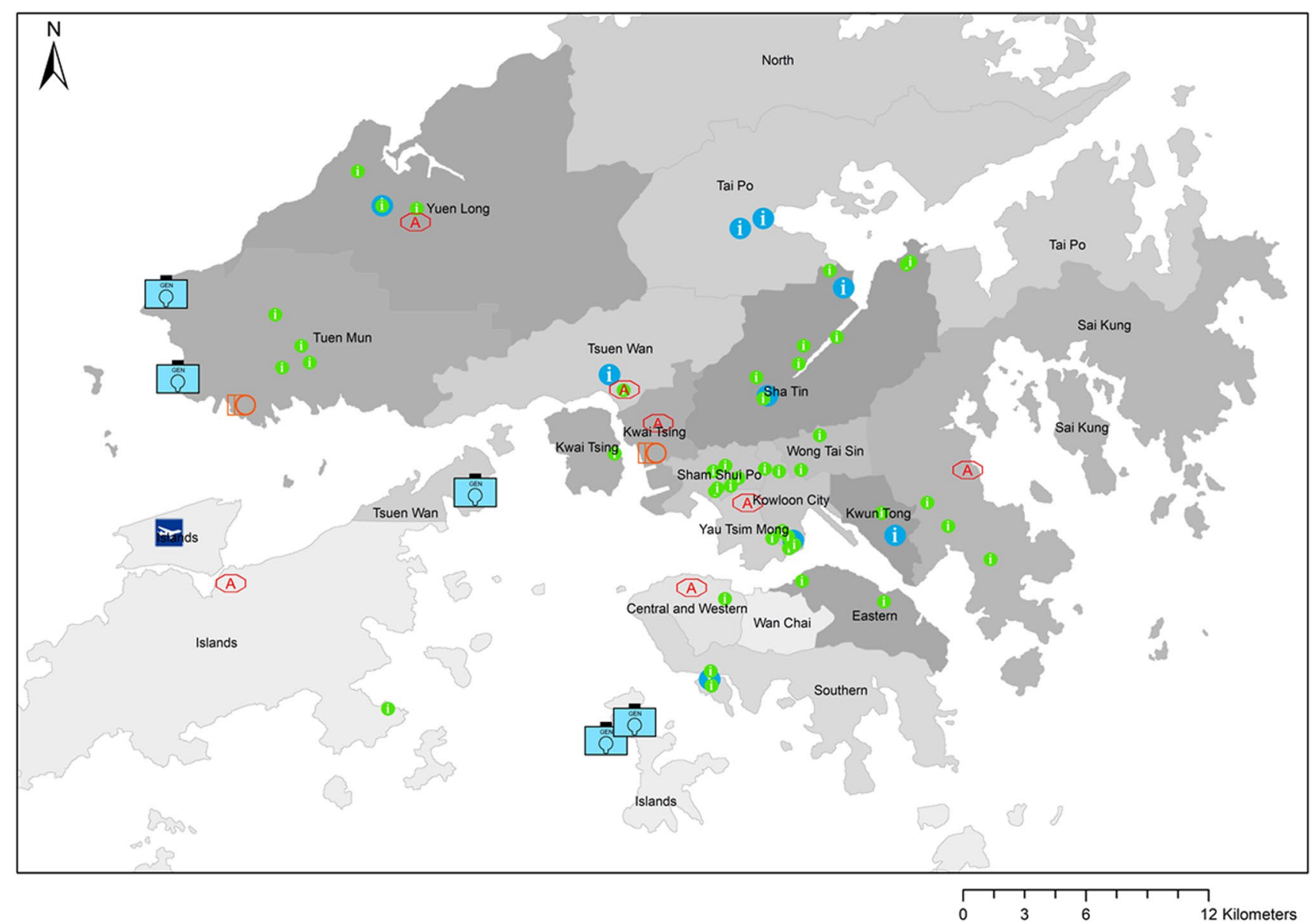

Fig. 1 Map of the study area in Hong Kong (Notes: green: session 1; blue: session 2; circle A: general stations for air quality monitoring; dark blue square: airport; light blue rectangular: power stations)

two-consecutive day sampling event during the summer and (or) winter season (session 1), respectively, leading to 161 personal $\mathrm{PM}_{2.5}$ samples. Further, thirteen participants were included in an additional longitudinal personal monitoring program for over one year (session 2), with a total of 243 personal $\mathrm{PM}_{2.5}$ samples collected. A questionnaire survey was used to collect general covariate information (including age, gender, height, weight, and occupation) from study participants. In addition, each participant was asked to complete a 24-h time-activity diary denoting their locations (e.g., indoors, outdoors, in transit) and activity patterns (e.g., sitting, standing, walking, running, driving, riding, housework) every $15-30 \mathrm{~min}$.

\section{Survey and behavioral research ethics}

The current research protocol was reviewed and approved by the Research Ethics Committee of The Chinese University of Hong Kong. All subjects provided their written informed consent before participation.

\section{Personal sample collection and chemical analyses}

\section{Personal $\mathrm{PM}_{2.5}$ exposure}

A personal environmental monitor (PEM) connected to a sampling pump was used for Personal $\mathrm{PM}_{2.5}$ sample collection. The PEM was loaded with a Teflon filter (37-mm, Pall Corp., NY, USA), and the pump was operated continuously for twenty-four hours $(24 \mathrm{~h})$ at a flow rate of $10( \pm 0.5) \mathrm{L} /$ min. Personal exposure was measured within the breathing zone of the participant, with the PEM located directly below the nose/mouth. Participants were instructed to wear the PEM for as much time as possible throughout the day but were allowed to place the sampler nearby when they were at home or in the workplace. Fig. 1 shows the study area and the subjects' residential location.

\section{Filter analyses}

Gravimetric analyses were performed using a microbalance (Model MC 5-0CE, Sartorius AG, Goettingen, 
Table 1 Study design, characteristics related to individual activities and inhalation rate of participants

\begin{tabular}{|c|c|c|}
\hline & Session 1 & Session 2 \\
\hline Sampling date & 4 July-Oct 2014 and Dec 2014-Mar 2015 & 25 April 2014-7 June 2015 \\
\hline Sampling frequency & Two-day sampling from each participant & Every-six day for each participant \\
\hline Temperature $\left({ }^{\circ} \mathrm{C}\right)^{\mathrm{a}}$ & $24.1 \pm 4.7$ & \\
\hline Relative humidity (\%) & $79.8 \pm 11.1$ & \\
\hline Rainfall (mm) & $0-122.1$ & \\
\hline Wind speed $(\mathrm{m} / \mathrm{s})$ & $2.9 \pm 1.7$ & \\
\hline Analyzed components & $\mathrm{PM}_{2.5}, \mathrm{OC}, \mathrm{EC}$, water-soluble ions, metals & $\mathrm{PM}_{2.5}$, metals \\
\hline Study participants $(\mathrm{N})$ & 48 & 13 \\
\hline Female $(\%)$ & $47.9 \%$ & $46.2 \%$ \\
\hline Male $(\%)$ & $52.1 \%$ & $53.8 \%$ \\
\hline Age (years) $(\text { Mean } \pm \mathrm{SD})^{\mathrm{b}}$ & $33 \pm 15$ & $36 \pm 16$ \\
\hline 18 44 years & $70.8 \%$ & $61.5 \%$ \\
\hline $45 \sim 60$ years & $18.8 \%$ & $38.5 \%$ \\
\hline$>61$ years & $10.4 \%$ & 0 \\
\hline Weight $(\mathrm{kg})($ Mean $\pm \mathrm{SD})$ & $60.7 \pm 10.5$ & $67.0 \pm 16.0$ \\
\hline Male & $65.1 \pm 11.1$ & $74.7 \pm 15.7$ \\
\hline Female & $56.0 \pm 7.6$ & $57.9 \pm 11.6$ \\
\hline Non-smokers (Yes/No, \%) & Yes, $100 \%$ & Yes, $100 \%$ \\
\hline Time activity $^{\mathrm{d}}$ & $\mathrm{N}^{\mathrm{c}}=161$ & $\mathrm{~N}^{\mathrm{c}}=229$ \\
\hline Indoors, total $(\%)($ Mean \pm SD) & $89.3 \pm 14.0$ & $84.1 \pm 14.5$ \\
\hline Indoors, at home $(\%)$ & $71.4 \pm 22.7$ & $71.5 \pm 19.2$ \\
\hline Sleeping $(\%)$ & $37.8 \pm 7.9$ & $36.7 \pm 7.2$ \\
\hline Sitting/Standing awake (\%) & $25.5 \pm 15.8$ & $24.8 \pm 16.8$ \\
\hline Housework (cleaning, cooking) (\%) & $4.3 \pm 5.7$ & $8.0 \pm 6.1$ \\
\hline Commuting by public transport (\%) & $5.0 \pm 9.0^{c}$ & $4.0 \pm 4.3$ \\
\hline Walking $(\%)$ & $3.9 \pm 5.4$ & $5.9 \pm 7.2$ \\
\hline Running (\%) & $1.3 \pm 6.5$ & $2.4 \pm 4.9$ \\
\hline Inhalation rate $\left(\mathrm{m}^{3} / \mathrm{day}\right)^{\mathrm{e}}$ & $18.0 \pm 3.3$ & $18.9 \pm 3.2$ \\
\hline Male & $19.2 \pm 3.2$ & $19.6 \pm 3.1$ \\
\hline Female & $16.7 \pm 2.8$ & $17.9 \pm 2.8$ \\
\hline
\end{tabular}

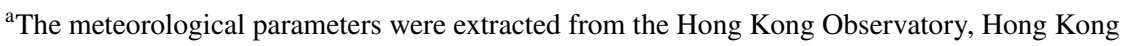

${ }^{\mathrm{b}}$ Mean \pm standard deviation

${ }^{\mathrm{c}}$ Number of activity diary collected from study participants during each sampling session

${ }^{\mathrm{d}}$ Data were extracted from self-administered activity diaries from participants. Mean values are weighted averages based on individual 15-min intervals on a daily basis for each session

${ }^{\mathrm{e}}$ Time-weighted inhalation rate

Germany) to measure personal $\mathrm{PM}_{2.5}$ mass on Teflon filters. Metal(loid) components (from sodium to lead) were analyzed using an energy dispersive X-ray fluorescence analyzer (ED-XRF, Epsilon 5, PANalytical Company, Netherlands) from the Teflon filters (Chow and Watson 2012). Though metal concentrations collected from ambient air have been reported previously (Chen et al. 2019a), this study only focused on personal exposure to heavy metal(loid)s. Eight heavy metal(loid)s (HMs) (including $\mathrm{V}, \mathrm{Cr}, \mathrm{Mn}, \mathrm{Ni}, \mathrm{Cu}, \mathrm{Zn}, \mathrm{Pb}$, and As) were further characterized. Method detection limits (MDLs) for these metal(loid) $\mathrm{s}$ were in the range of $0.1-1.0 \mathrm{ng} / \mathrm{m}^{3}$ (Table $\mathrm{S} 1$ ), and they were detectable (e.g., $>$ MDLs) for $85 \%$ of the samples except $\mathrm{Cr}$ and As ( 58-67\%) (Table 2). Hexavalent chromium [Cr (VI)] is more toxic than $\mathrm{Cr}$ (III), and $\mathrm{Cr}$ (VI) ((e.g., calculated as one-seventh of total $\mathrm{Cr}$ exposure concentration) is used for cancer risk estimation in the current study. Co and $\mathrm{Cd}$ were not detectable in personal $\mathrm{PM}_{2.5}$ and were thus excluded from data analysis. Standard quality assurance and quality control protocols for personal measurement, gravimetric determination, and chemical analyses were strictly followed. 
Table 2 Heavy metal(loid)s and associated toxicity values via the inhalation route

\begin{tabular}{|c|c|c|c|c|c|c|c|}
\hline & $\operatorname{RfC}\left(\mathrm{mg} / \mathrm{m}^{3}\right)^{\mathrm{g}}$ & Source & $\begin{array}{l}\text { Inhalation Unit } \\
\text { Risk }\left(\mathrm{IUR}^{\mathrm{j}}\right)(\mu \mathrm{g} / \\
\left.\mathrm{m}^{3}\right)^{-1}\end{array}$ & $\begin{array}{l}\text { Weight of } \\
\text { evidence (IRIS } \\
\text { IARC }^{\circ} \text { ) }\end{array}$ & $\begin{array}{l}\text { Critical organ or } \\
\text { effect via inhala- } \\
\text { tion }\end{array}$ & $\begin{array}{l}\mathrm{SF}_{\text {inh }}{ }^{\mathrm{h}}(\mathrm{mg} / \mathrm{kg} \\
\text { day })^{-1}\end{array}$ & Source \\
\hline Vanadium (V) & $1.00 \mathrm{E}-04$ & $\operatorname{ATSDR}^{\mathrm{d}}$ & $-{ }^{\mathrm{i}}$ & $-{ }^{\mathrm{i}}$ & Respiratory tract & $-{ }^{\mathrm{i}}$ & $\begin{array}{l}\operatorname{ATSDR}^{\mathrm{d}}(\mathrm{rat}) ; \\
\operatorname{RIVM}^{\mathrm{e}} \\
\text { (human) }\end{array}$ \\
\hline $\begin{array}{l}\text { Chromium }(\mathrm{Cr} \\
(\mathrm{VI}))\end{array}$ & $1.00 \mathrm{E}-04$ & U.S. EPA ${ }^{\mathrm{a}}, 2010$ & $1.20 \mathrm{E}-02$ & $\mathrm{~A}^{\mathrm{l}} ; 1$ & Respiratory tract & $5.10 \mathrm{E}+02^{\mathrm{b}}$ & $\begin{array}{l}\text { CalEPA }^{\text {b }} \text { U.S. } \\
\text { EPA }^{\text {a }}\end{array}$ \\
\hline $\begin{array}{l}\text { Manganese } \\
(\mathrm{Mn})\end{array}$ & $5.00 \mathrm{E}-05$ & U.S. EPA & $-{ }^{\mathrm{i}}$ & $\mathrm{D}^{\mathrm{m}} ; 3$ & $\begin{array}{l}\text { Neurobehavioral } \\
\text { function }\end{array}$ & $-^{\mathrm{i}}$ & U.S. EPA \\
\hline Nickel (Ni) & $1.40 \mathrm{E}-05$ & CalEPA $^{\mathrm{b}}$ & $2.40 \mathrm{E}-04$ & $\mathrm{~A} ; 1$ & Lung & $9.10 \mathrm{E}-01^{\mathrm{b}}$ & $\begin{array}{l}\text { CalEPA; U.S. } \\
\text { EPA }\end{array}$ \\
\hline Copper $(\mathrm{Cu})$ & $2.00 \mathrm{E}-05$ & CalEPA & $-{ }^{\mathrm{i}}$ & $\mathrm{D} ; 3$ & $\begin{array}{l}\text { Respiratory } \\
\text { system }\end{array}$ & $-{ }^{\mathrm{i}}$ & U.S. EPA \\
\hline Zinc $(\mathrm{Zn})$ & $9.00 \mathrm{E}-04$ & CalEPA, 1997 & $-{ }^{\mathrm{i}}$ & $\mathrm{D} ; 3$ & Accurate effects ${ }^{\mathrm{n}}$ & $-{ }^{\mathrm{i}}$ & U.S. EPA \\
\hline Arsenic (As) & $2.00 \mathrm{E}-05$ & CalEPA, 2008 & 4.30E-03 & $\mathrm{A} ; 1$ & Lung & $1.20 \mathrm{E}+01^{\mathrm{b}}$ & $\begin{array}{l}\text { CalEPA; U.S. } \\
\text { EPA }\end{array}$ \\
\hline Lead $(\mathrm{Pb})$ & $5.00 \mathrm{E}-04$ & OEHHA $^{\mathrm{c}}, 2009$ & $-{ }^{\mathrm{i}}$ & $\mathrm{B} 2^{\mathrm{k}} ; 2 \mathrm{~A}$ & $\begin{array}{l}\text { Central nerve } \\
\text { system, kidney }\end{array}$ & $-{ }^{\mathrm{i}}$ & U.S. EPA ${ }^{f}$ \\
\hline
\end{tabular}

${ }^{a}$ U.S. EPA, United States Environmental Protection Agency

${ }^{\mathrm{b}}$ Cal EPA: California Environmental Protection Agency, U.S

${ }^{\mathrm{c}}$ OEHHA: The Office of Environmental of Health Hazard Assessment, California, U.S

${ }^{\mathrm{d}}$ ATSDR: The Agency for Toxic Substances and Disease Registry, U.S

${ }^{e}$ RIVM: The Dutch National Institute for Public Health and the Environment

${ }^{\mathrm{f}}$ No studies are available on cancer in animals exposed to lead via the inhalation or dermal routes

${ }^{\mathrm{g}}$ Chronic inhalation reference concentration (RfC)

${ }^{\mathrm{h}}$ Inhalation Slope Factor $\left(\mathrm{SF}_{\text {inh }}\right)$

${ }^{\mathrm{i}}$ Not available

${ }^{\mathrm{j} I n t e g r a t e d ~ R i s k ~ I n f o r m a t i o n ~ S y s t e m ~(I R I S), ~ U . S ~ E P A ~}$

${ }^{\mathrm{k}}$ Group B2, a probable human carcinogen, and U.S. EPA has not established an IUR for lead $(\mathrm{Pb})$

${ }^{\mathrm{l}}$ Group A: human carcinogen

${ }^{\mathrm{m}}$ Group D: not classifiable as to human carcinogenicity

${ }^{\mathrm{n}}$ Acute inhalation exposure to high levels of zinc has resulted in a disease characterized by dryness of the throat, coughing, chest pain, and dyspnea

${ }^{\circ}$ IARC: The international Agency for Research on Cancer

\section{Inhalation health risk assessment}

\section{Estimation of exposure to heavy metal(loid)s through inhalation}

There is extensive evidence about the health risks posed by exposure to heavy metals via the inhalation route. Fig. 2 illustrates the health risk assessment diagram, derived from the U.S. Environmental Protection Agency (EPA) Risk Assessment Guidance for human health risk evaluation related to inhalation exposure (Superfund, Part F) to hazardous air pollutants (e.g., airborne metal components) (U.S. EPA 2009). Toxicological effects of source-specific $\mathrm{PM}_{2.5}$ in personal exposure and heavy metal exposure in the public transport system of Hong Kong (e.g., buses, mass transit railway) were demonstrated in other publications
(Chen et al. 2020a, 2021). In this study, non-cancer risks (characterized by hazard quotient and hazard index) and cancer risks of HMs via inhalation route were assessed for adult participants.

Table 2 shows inhalation toxicity values for the targeted HMs, including chronic inhalation reference concentrations (RfC), inhalation unit risk (IUR), and carcinogen classification. $\mathrm{Cr}(\mathrm{VI}), \mathrm{Ni}$, and As are classified as group 1 carcinogens by the International Agency for Research on Cancer (IARC 2012). $\mathrm{Pb}$ is assigned as group 2A, referring to "probably carcinogenic" to humans. The corresponding toxic values for these HMs were adapted from the Integrated Risk Information System (IRIS) proposed by the U.S. EPA unless otherwise specified. Cancer risks of $\mathrm{Mn}, \mathrm{Cu}, \mathrm{Zn}$, and $\mathrm{Pb}$ are not further discussed because IURs for these metals are not available. 


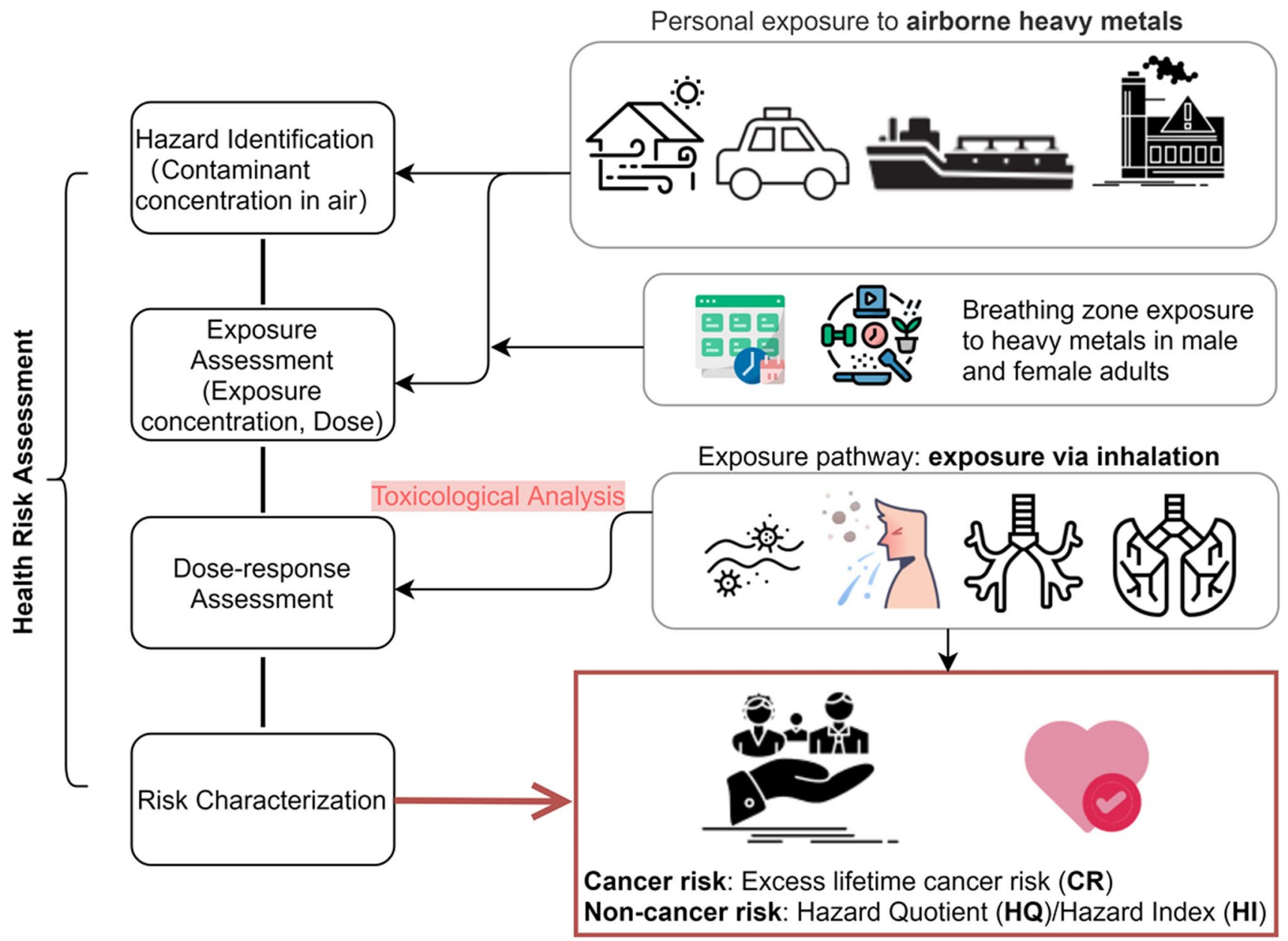

Fig. 2 Characterization of risk occurrence of airborne heavy metal(loid)s in adults

Exposure concentrations $\left(\mathrm{EC}_{i}, \mu \mathrm{g} / \mathrm{m}^{3}\right)$ of HMs attributable to inhalation were estimated using the following equation:

$\mathrm{ECi}=\frac{C i \times E T \times E F \times E D}{A T}$

where $C_{i}$ represents the concentration of metals in personal $\mathrm{PM}_{2.5}\left(\mu \mathrm{g} / \mathrm{m}^{3}\right)$; ET is the exposure time ( $24 \mathrm{~h} /$ day); EF refers to exposure frequency ( 315 days/year for metals in this study; Table 2); ED is the exposure duration in years (e.g., 30 years for adults); AT is the averaging time for non-carcinogens $(\mathrm{ED} \times 365$ days/year $\times 24 \mathrm{~h} /$ day $)$; for carcinogenic heavy metals [Cr (VI), Ni, and As], AT is the average lifetime in years (i.e., 70 years $\times 365$ days/year $\times$ 24 h/day) (Phillips and Moya 2013; U.S. Environmental Protection Agency 2011).

The chronic daily inhalation intake $\left(\mathrm{CDI}_{i n h}, \mathrm{mg} / \mathrm{kg}\right.$ day) of $\mathrm{HMs}$ in personal $\mathrm{PM}_{2.5}$ was defined as follows:
$C D I_{i n h}=\frac{E C i \times \operatorname{InhR} \times E F \times E D}{\mathrm{BW} \times A T \times C F}$

where inhalation rate $\left(I n h R, \mathrm{~m}^{3} /\right.$ day $)$ was calculated based on the Exposure Factors Handbook for specific personal activities (U.S. Environmental Protection Agency 2011). Furthermore, personal information (e.g., body weight (BW), $\mathrm{kg}$ ) was extracted from the questionnaire-based survey and self-reported activity diaries of study participants (e.g., see Table 1 and Table S2). Table S3 presents the results of the chronic daily intake of HMs.

\section{Characterization of cancer and non-cancer risk}

Human risk assessment was performed to estimate non-cancer risk and cancer risk of heavy metal exposures via the inhalation route. The non-cancer risk of HMs via inhalation 
was estimated using a hazard quotient (HQ), with the following equation applied:

$H Q i=\frac{E C i}{\operatorname{RfCi} \times C F}$

where $\mathrm{RfC}_{i}$ is the chronic inhalation reference concentration $\left(\mathrm{mg} / \mathrm{m}^{3}\right.$ ) of the targeted metal component (as reported in Table 2), and CF is the conversion factor $(1000 \mu \mathrm{g} / \mathrm{mg})$. HQ value $>1$ suggests a potential non-cancer risk exposure to a particular metal component. HQ $<1$ indicates that adverse health outcomes are not expected from exposure to the metal component. Further, the hazard index $\left(H I=\sum_{1}^{n} H Q_{i}\right)$ (e.g., toxic metal component $i$ ) was applied to estimate the noncancer risks of the studied heavy metal(loid)s. An HI value $>1$ indicates the potential for non-cancer risks, and metal mixture exposures could be of public health concern.

Previous studies have applied $\mathrm{CDI}_{i n h}$ and inhalation cancer slope factors (see Table 2) to estimate the potential cancer risk of hazardous air pollutants (Cao et al. 2016). However, in 2003, the U.S. EPA Superfund Program updated the inhalation risk paradigm, which suggested air pollutants reaching the target site of the human body is not a simple function of inhalation rate and body weight. Thus, the document recommended using exposure concentrations rather than inhalation intake of the targeted chemicals to assess the cancer risk of inhaled contaminants in ambient air (U.S. EPA 2009). As a result, more recent studies applied IURs to determine cancer risks of hazardous air pollutants (Liu et al. 2018; U.S. EPA 2007). In this research, excess lifetime cancer risk posed by heavy metal(loid)s via inhalation $\left(\mathrm{CR}_{i n h}\right)$ were thus calculated using the updated equation:

$C R_{i n h}=E C i \times I U R i$

where $\mathrm{EC}_{i}$ and $\mathrm{IUR}_{i}$ refer to exposure concentration and inhalation unit risk of the carcinogenic heavy metal(loid)s $\left(\mu \mathrm{g} / \mathrm{m}^{3}\right)$, respectively. $\mathrm{CR}_{i n h}$ of $1 \times 10^{-6}$ is considered a negligible risk. $\mathrm{CR}_{\text {inh }}$ values between $1 \times 10^{-6}$ and $1 \times 10^{-4}$ are considered acceptable or tolerable for regulatory purposes, while $\mathrm{CR}_{\text {inh }}$ above $1 \times 10^{-4}$ is likely to be harmful to human beings, and remediation may be desirable.

\section{Statistical analyses}

The Kolmogorov-Smirnov test and visual inspection of the histograms were applied to assess the normality of exposure parameters, and exposure concentrations of the targeted heavy metals were left-censored. We used the Mann-Whitney $U t$ test to assess differences in exposure concentrations and chronic daily intake of the targeted metals across male and female participants. Pearson correlation coefficients $(r)$ was applied to investigate the associations of HMs in personal $\mathrm{PM}_{2.5}$. A $p$ value $<0.05$ was considered statistically significant. We employed principal component analysis (PCA) for source identification of HMs in personal $\mathrm{PM}_{2.5}$. Varimax normalized rotation was performed to maximize or minimize the factor loadings of principal components (PCs). The PCs with an eigenvalue $>1$ entered in the source identification analysis. The current study focused on the targeted heavy metals exposures across both sampling sessions.

\section{Uncertainty analysis}

The Monte Carlo simulation was performed 10,000 times to assess the uncertainty associated with cancer risk assessment. This stochastic risk analysis technique captures the variations (e.g., log-normal distribution) in exposure concentrations among individuals and the risk distributions instead of a single point value, thereby providing a clear picture of health risk estimates in the adult population. The IUR values for $\mathrm{Cr}(\mathrm{VI}), \mathrm{Ni}$, and $\mathrm{As}$ are derived from the U.S. EPA's IRIS, which is defined as the upper-bound excess lifetime cancer risk due to continuous exposure to human carcinogens in the atmosphere. PCA and Monte Carlo simulations were performed using SPSS statistics (V26.0, IBM SPSS Statistics).

\section{Results}

\section{Characteristics of study subjects and time-activity patterns}

Sixty-one healthy adults participated in personal monitoring from April 2015 to June 2015 (Table 1). Male and female participants were equally represented, with no significant age differences $(p>0.05)$. Table 1 shows the summary characteristics of time-activity patterns for study participants across the sampling sessions. All study subjects were non-smokers and without ETS exposure in different indoor microenvironments (e.g., home, office, school, indoors in public places). These subjects spent $84.1-89.3 \%$ of their daily time indoors (including $\sim 71 \%$ at home), and $36.7-37.8 \%(\sim 8 \mathrm{~h})$ of the time was spent sleeping within their residences. No statistical variations were shown in activity patterns for male and female participants or across sampling sessions. A small portion of time was spent on housework (4.3-8.0\%). The average time in transit varied from $4.0 \%$ (standard deviation, $\mathrm{SD}=7.8 \%$ ) to $5.0 \%$ ( $\mathrm{SD}=$ $10.0 \%$ ); Metro and buses were the most common commuting modes used by Hong Kong residents.

Table 1 also shows the time-weighted inhalation rates estimated from daily activities for these study participants. The calculated average inhalation rates for the male and female subjects were $19.2-19.6 \mathrm{~m}^{3} /$ day and $16.7-17.9 \mathrm{~m}^{3} /$ day, respectively. Wang et al. (2009) estimated the average 
inhalation rates in the Chinese adult population (male: 19.0 $\mathrm{m}^{3} /$ day; female $14.2 \mathrm{~m}^{3} /$ day). These results were slightly higher than those reported in the U.S. EPA's Exposure Factors Handbook (average of male and female adults combined $=15.2 \mathrm{~m}^{3} /$ day) (Phillips and Moya 2013).

\section{Variation in exposure to heavy metals through inhalation}

Table 3 shows the summary statistics of personal exposure to HMs in $\mathrm{PM}_{2.5}$, among which $\mathrm{Cr}(\mathrm{VI}), \mathrm{Ni}$ and As are confirmed carcinogens via inhalation. Study results regarding personal $\mathrm{PM}_{2.5}$ exposures were reported in previous publications (Chen et al. 2019a, 2018). The average concentrations of the studied heavy metal(loid)s $\left(192 \times 10^{-3}\right.$ $\left.\mu \mathrm{g} / \mathrm{m}^{3} ; \mathrm{SD}=205 \times 10^{-3} \mu \mathrm{g} / \mathrm{m}^{3}\right)$ contribute a small fraction of personal $\mathrm{PM}_{2.5}$ mass $(0.57 \%, \mathrm{SD}=0.72 \%)$. These metal(loid)s, individually and in combination (pooled data across two sessions), followed the order of $\mathrm{Zn}\left(118 \times 10^{-3}\right.$ $\left.\mu \mathrm{g} / \mathrm{m}^{3}\right)>\mathrm{Pb}\left(25.2 \times 10^{-3} \mu \mathrm{g} / \mathrm{m}^{3}\right)>\mathrm{Cu}\left(18.2 \times 10^{-3} \mu \mathrm{g} /\right.$ $\left.\mathrm{m}^{3}\right)>\mathrm{V}\left(15.0 \times 10^{-3} \mu \mathrm{g} / \mathrm{m}^{3}\right)>\mathrm{Mn}\left(12.2 \times 10^{-3} \mu \mathrm{g} / \mathrm{m}^{3}\right)>$ Ni $\left(4.0 \times 10^{-3} \mu \mathrm{g} / \mathrm{m}^{3}\right)>\mathrm{Cr}\left(3.0 \times 10^{-3} \mu \mathrm{g} / \mathrm{m}^{3}\right)>$ As $(1.9$ $\left.\times 10^{-3} \mu \mathrm{g} / \mathrm{m}^{3}\right)$. Also, annual average exposure concentrations of $\mathrm{Cr}, \mathrm{Ni}, \mathrm{Cu}$, and $\mathrm{As}$ (in session 2) were significantly higher than monthly average exposures (i.e., in session $1)$. For most metals, exposures spanned several orders of

Table 3 Summary statistics of personal exposure to heavy metal(loid)s (ng/m³) in $\mathrm{PM}_{2.5}$ across sampling sessions

\begin{tabular}{|c|c|c|c|c|c|c|c|c|c|c|c|c|c|}
\hline$\left(\times 10^{-3}\right) \mu \mathrm{g} / \mathrm{m}^{3}$ & Metals & Mean & $\mathrm{SD}^{\mathrm{a}}$ & Minimum & $5^{\text {th }}$ & $25^{\text {th }}$ & Median & $75^{\text {th }}$ & $95^{\text {th }}$ & Maximum & $\mathrm{N}^{\mathrm{c}}$ & $>\operatorname{MDLs}^{\mathrm{b}}(\%)$ & $p$ value $^{\mathrm{d}}$ \\
\hline \multirow[t]{8}{*}{ Session 1} & $\mathrm{~V}$ & 14.1 & 15.9 & 0.6 & 1.4 & 4.3 & 7.6 & 16.7 & 53.2 & 76.6 & 161 & 96.9 & \\
\hline & $\mathrm{Cr}(\mathrm{Cr} \mathrm{VI})^{\mathrm{e}}$ & $2.0(0.28)^{\mathrm{f}}$ & 2.1 & 0.5 & 0.5 & 0.5 & 1.1 & 2.5 & 6.6 & 11.4 & 161 & 53.4 & $* * *$ \\
\hline & Mn & 13.1 & 12.7 & 0.4 & 0.4 & 5.8 & 12.3 & 17.3 & 25.8 & 133 & 161 & 94.4 & $* *$ \\
\hline & Nif & 1.8 & 1.8 & 0.1 & 0.1 & 0.6 & 1.0 & 2.1 & 6.6 & 9.5 & 161 & 88.8 & $* * *$ \\
\hline & $\mathrm{Cu}$ & 22.1 & 22.6 & 0.3 & 1.0 & 8.2 & 15.9 & 27.2 & 68.4 & 138 & 161 & 95.7 & $* * *$ \\
\hline & $\mathrm{Zn}$ & 134 & 219 & 2.0 & 7.0 & 39 & 104 & 165 & 307 & 2456 & 161 & 100 & \\
\hline & $\mathrm{As}^{\mathrm{g}}$ & 0.9 & 0.8 & 0.2 & 0.2 & 0.2 & 0.8 & 1.4 & 2.6 & 4.0 & 161 & 64.0 & $* * *$ \\
\hline & $\mathrm{Pb}$ & 25.2 & 22.8 & 0.7 & 0.7 & 4.4 & 20.9 & 38.4 & 68.5 & 97.2 & 161 & 85.7 & $* *$ \\
\hline \multirow[t]{8}{*}{ Session 2} & V & 15.6 & 15.6 & 1.3 & 2.4 & 5.7 & 11.2 & 19.4 & 43.4 & 94.3 & 234 & 96.7 & \\
\hline & $\mathrm{Cr}(\mathrm{Cr} \mathrm{VI}) \mathrm{e}$ & $3.9(0.56)^{f}$ & 3.9 & 0.9 & 1.1 & 1.8 & 2.7 & 4.5 & 10.3 & 35.0 & 184 & 76.0 & $<0.001$ \\
\hline & Mn & 11.6 & 8.9 & 0.9 & 1.3 & 4.0 & 10.5 & 15.6 & 27.8 & 56.0 & 222 & 91.7 & 0.009 \\
\hline & Nif & 5.6 & 4.6 & 0.4 & 1.1 & 2.3 & 4.1 & 7.9 & 15.5 & 25.4 & 233 & 96.3 & $<0.001$ \\
\hline & $\mathrm{Cu}$ & 15.5 & 20.5 & 0.7 & 1.6 & 4.8 & 10.7 & 18.5 & 45.8 & 250 & 237 & 97.9 & $<0.001$ \\
\hline & $\mathrm{Zn}$ & 107 & 134 & 1.0 & 7.0 & 25 & 72 & 146 & 295 & 1366 & 242 & 100 & \\
\hline & Asg & 3.1 & 2.1 & 0.8 & 0.9 & 1.7 & 2.5 & 3.8 & 6.8 & 13.0 & 132 & 54.5 & $<0.001$ \\
\hline & $\mathrm{Pb}$ & 25.3 & 36.3 & 1.5 & 1.9 & 4.6 & 18.9 & 34.7 & 73.4 & 441 & 207 & 85.5 & 0.008 \\
\hline \multirow[t]{8}{*}{ Total } & $\mathrm{V}$ & 15.0 & 15.7 & 0.6 & 1.8 & 5.2 & 9.8 & 19.0 & 49.2 & 94.3 & 395 & 96.8 & \\
\hline & $\mathrm{Cr}(\mathrm{Cr} \mathrm{VI}) \mathrm{e}$ & $3.0(0.43)^{f}$ & 3.3 & 0.5 & 0.5 & 1.0 & 2.0 & 3.8 & 9.2 & 35.0 & 345 & 67.0 & \\
\hline & $\mathrm{Mn}$ & 12.2 & 10.7 & 0.4 & 1.0 & 5.0 & 11.4 & 16.5 & 26.1 & 133 & 383 & 92.8 & \\
\hline & $\mathrm{Ni}$ & 4.0 & 4.2 & 0.1 & 0.2 & 1.2 & 2.5 & 5.4 & 11.8 & 25.4 & 394 & 93.3 & \\
\hline & $\mathrm{Cu}$ & 18.2 & 21.6 & 0.3 & 1.5 & 6.2 & 13.9 & 23.1 & 48.9 & 250 & 398 & 97.0 & \\
\hline & $\mathrm{Zn}$ & 118 & 173 & 0.6 & 7.5 & 32 & 88.1 & 155 & 295 & 2456 & 403 & 100 & \\
\hline & As & 1.9 & 1.9 & 0.2 & 0.2 & 0.5 & 1.4 & 2.5 & 5.2 & 13.0 & 293 & 58.3 & \\
\hline & $\mathrm{Pb}$ & 25.2 & 31.1 & 0.7 & 0.7 & 4.5 & 19.6 & 36.5 & 69.1 & 441 & 368 & 85.6 & \\
\hline
\end{tabular}

${ }^{\text {a }} \mathrm{SD}$ refers to standard deviation

${ }^{b}$ MDLs refers to the method detection limit. An average of \% MDLs (86\%) of the targeted metals was applied to assess the exposure frequency $(\mathrm{EF})$ of the metals in the current study $(\mathrm{EF}=0.86 \times 365$ days/year $=315$ days/year $)$

${ }^{\mathrm{c}} \mathrm{N}$ refers to the number of valid data, and concentrations below the MDLs were discarded

${ }^{\mathrm{d}}$ Differences across sampling sessions were statistically significant at a significance level of $0.05\left({ }^{* * *} p\right.$ value $<0.001 ;{ }^{* *} p$ value $<0.01 ;{ }^{*} p$ value $<0.05)$

${ }^{\mathrm{e}} \mathrm{Cr}(\mathrm{VI})=0.25 \mathrm{ng} / \mathrm{m}^{3}$ (the WHO estimated reference level); concentration refers to an excess lifetime cancer risk of $1 \times 10^{-6}$

${ }^{\mathrm{f}} \mathrm{Ni}=25 \mathrm{ng} / \mathrm{m}^{3}$ (the WHO estimated reference level); concentration refers to an excess lifetime cancer risk of $1 \times 10^{-6}$

${ }^{\mathrm{g}} \mathrm{As}=6.6 \mathrm{ng} / \mathrm{m}^{3}$ (the WHO estimated reference level); concentration refers to an excess lifetime cancer risk of $1 \times 10^{-6}$

${ }^{\mathrm{f}} \mathrm{The}$ concentration of $\mathrm{Cr}$ (VI) used for the cancer risk assessment was calculated as one-seventh of total $\mathrm{Cr}$ concentration 
magnitude; the range of $25^{\text {th }}$ to $75^{\text {th }}$ was no more than one order of magnitude ( 4.2). Table S3 shows chronic daily intake of metal(loid)s via inhalation $\left(\mathrm{CDI}_{\text {inh }}\right)$. Consistent with HMs exposure concentrations, $\mathrm{CDI}_{i n h}$ of the targeted metals exhibited the same patterns, following the order of $\mathrm{Zn}>\mathrm{Pb}>\mathrm{Cu}>\mathrm{V}>\mathrm{Mn}>\mathrm{Ni}>\mathrm{Cr}>$ As.

\section{Source identification using principal component analysis}

We employed PCA to identify sources of HMs in personal $\mathrm{PM}_{2.5}$, with the results (e.g., source profiles) presented in Table 4. Further, Table S5 presents the Pearson correlation $(r)$ matrix of the targeted metals. Three principal components were extracted by PCA, with a total variance of $71.3 \%$. The first component had high loading of $\mathrm{As}, \mathrm{Pb}$, and $\mathrm{Cr}$, which accounted for $24.8 \%$ of the total variance. A moderate correlation between As and $\mathrm{Pb}(r=0.51 ; p<$ 0.05 ) was shown (Table $\mathrm{S} 5$ ). In contrast, $\mathrm{Cr}$ and $\mathrm{Cu}$ exhibited weak correlations with As $(r: 0.20-0.40)$ and $\mathrm{Pb}(r$ : $0.27-0.29$ ), indicating a mixed source contribution from these metals. $\mathrm{Cr}$ in the atmosphere primarily originated from regional pollution (e.g., from coal combustion) (Liu et al. 2018) and traffic-related pollution (e.g., street dust) (Huang et al. 2018) (Table S6). Cu originated mainly from industrial smelting process sources and vehicle emissions in urban areas. For comparison, Johansson et al. (2009) indicated that more than $90 \%$ of $\mathrm{Cu}$ from traffic emissions originated from brake wear. Therefore, component 1 was identified as a combination of regional pollution (characterized by coal combustion tracers of $\mathrm{As}$ and $\mathrm{Pb}$ ) and traffic-related pollution (e.g., non-tailpipe).

Strong associations were shown between $\mathrm{Ni}$ and $\mathrm{V}(r$ $=0.71 ; p<0.05)$ and $\mathrm{Mn}$ and $\mathrm{Zn}(r=0.86 ; p<0.05)$ (Table S5), respectively, suggesting these metals may originate from common sources. Component 2 was characterized by high factor loadings of $\mathrm{Mn}$ and $\mathrm{Zn}$ (explained $23.9 \%$ of the total variance) from regional pollution (e.g., steel industry). Component 3 accounted for $22.6 \%$ of the total variance and was characterized by high loading of $\mathrm{Ni}$ and $\mathrm{V}$, indicating shipping emissions.

\section{Health risk estimates of inhalation exposure to HMs}

\section{Non-cancer risk of HMs via inhalation}

Heavy metal(loid)s collected from individual participants were used to assess inhalation health risks. Table 5 shows the non-cancer risks (HQ and HI values) posed by targeted HMs via inhalation. Among these metal(loid)s, $\mathrm{Cu}$ had the highest HQ value of 0.79 (ranging from 0.67 to 0.95 ; SD $=0.93$ ). The non-cancer health risks of heavy metal(loid) $\mathrm{s}$ exposure followed the descending order of $\mathrm{Cu}>\mathrm{Mn}>$ $\mathrm{V}>\mathrm{Ni}>\mathrm{Zn}>\mathrm{Pb}>\mathrm{As}>\mathrm{Cr}$. In summary, the HI values for targeted metals (1.39) were higher than safe levels, suggesting substantial non-cancer risks posed by heavy metals for adults.
Table 4 Principal component analysis of personal exposure to heavy metal(loid)s in $\mathrm{PM}_{2.5}$

\begin{tabular}{|c|c|c|c|}
\hline Species & Component $1^{\mathrm{c}}$ & Component 2 & Component 3 \\
\hline V & $\mathrm{a}$ & $\mathrm{a}$ & 0.86 \\
\hline $\mathrm{Cr}$ & 0.71 & $\mathrm{a}$ & $\mathrm{a}$ \\
\hline $\mathrm{Mn}$ & a & 0.91 & $\mathrm{a}$ \\
\hline $\mathrm{Ni}$ & $\mathrm{a}$ & $\mathrm{a}$ & 0.94 \\
\hline $\mathrm{Cu}$ & 0.41 & a & $\mathrm{a}$ \\
\hline $\mathrm{Zn}$ & a & 0.95 & $\mathrm{a}$ \\
\hline As & 0.82 & $\mathrm{a}$ & $\mathrm{a}$ \\
\hline $\mathrm{Pb}$ & 0.68 & $\mathrm{a}$ & $\mathrm{a}$ \\
\hline Eigenvalue & 2.73 & 1.82 & 1.15 \\
\hline$\%$ of Variance ${ }^{\mathrm{b}}$ & 24.8 & 23.9 & 22.6 \\
\hline Cumulative $\%$ & 24.8 & 48.7 & 71.3 \\
\hline Possible sources ${ }^{\mathrm{d}}$ & $\begin{array}{l}\text { Regional pollution (coal combustion) } \\
\text { and vehicle emissions (e.g., non- } \\
\text { tailpipe) }\end{array}$ & $\begin{array}{l}\text { Regional pollution } \\
\text { (industry) and road } \\
\text { dust }\end{array}$ & Shipping emission \\
\hline
\end{tabular}

\footnotetext{
${ }^{\mathrm{a}}$ Factor loading between -0.40 and 0.40 is not shown

${ }^{\mathrm{b}} \%$ of the variance: percentage of variance explained by each factor

${ }^{\mathrm{c}}$ Principal component rotation method applied: Varimax with Kaiser normalization

${ }^{\mathrm{d}}$ Anthropogenic sources were shown in Table S7
} 


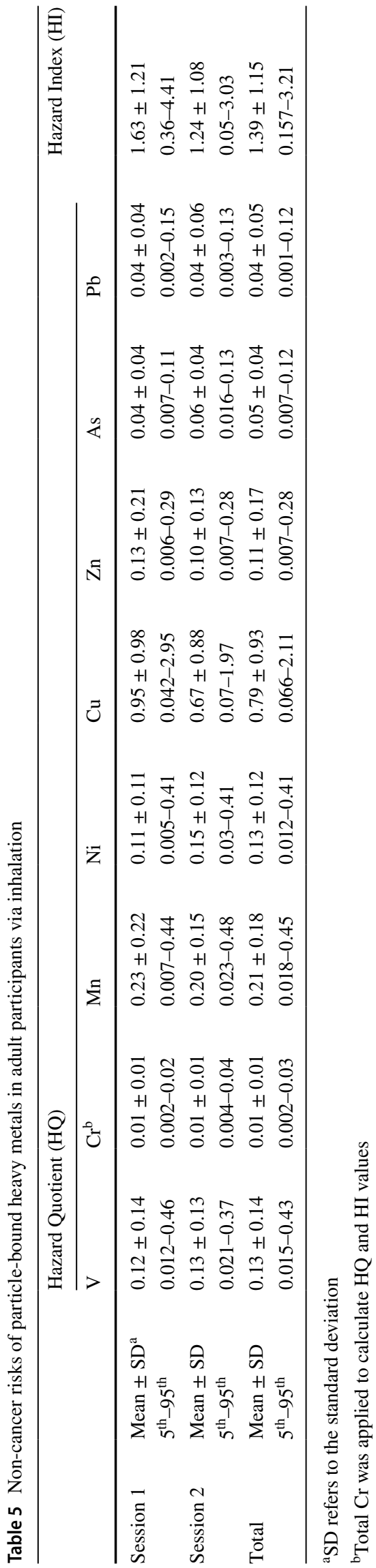

\section{Cancer risk}

$\mathrm{Cr}$ (VI), Ni, and As are human carcinogens (group 1) via inhalation. Table 6 presents the cancer risks of inhaling particulate $\mathrm{Cr}(\mathrm{VI}), \mathrm{Ni}$, and As in personal exposure conducted by adult participants. The $\mathrm{CR}_{\text {inh }}$ posed by personal As exposure via inhalation was the highest for these adult participants. The average and $95^{\text {th }}$ percentile values of $\mathrm{CR}_{\text {inh }}$ for As $\left(4.07 \times 10^{-6}\right.$ and $1.02 \times 10^{-5}$, respectively) exceeded the tolerable risk limit. These results indicate $\sim 10$ out of one million adults living in the study area may develop cancer from inhaling arsenic during their lifetime. The average and $95^{\text {th }}$ percentile values of $\mathrm{CR}_{i n h}$ for $\mathrm{Cr}(\mathrm{VI})\left(1.91 \times 10^{-6}\right)$ were higher than the acceptable risk level $\left(1 \times 10^{-6}\right)$. Also, $\mathrm{CR}_{i n h}$ for $\mathrm{Ni}\left(1.38 \times 10^{-6}\right)$ at the $95^{\text {th }}$ percentile exceeded the acceptable risk level. Consistent with the exposure concentrations, the cancer risks of $\mathrm{Ni}\left(1.38 \times 10^{-6}\right), \mathrm{Cr}(\mathrm{VI})$ $\left(6.56 \times 10^{-6}\right)$, and As $\left(1.09 \times 10^{-5}\right)$ at the $95^{\text {th }}$ percentile in session 2 were higher than those of session 1 (Table 6). These results further exemplify the toxic effects of heavy metals on human health, suggesting that long-term personal exposure to heavy metals warrants extensive investigation and possibly remediation.

The variability of exposure concentrations and IUR values could result in high uncertainty in health risk estimations. Therefore, we employed the Monte Carlo simulation to investigate the distribution of health risks for adults. For the frequency distribution of estimated $\mathrm{CR}_{i n h}$, log-normal distributions had the best fit for $\mathrm{Cr}$ (VI), Ni, and As. Fig. 3 illustrates the probability distribution of the estimated $\mathrm{CR}_{\text {inh }}$ of $\mathrm{Cr}(\mathrm{VI}), \mathrm{Ni}$, and As for adults. These results revealed the highest average cancer risks of $4.04 \times 10^{-6}$ for Ni, followed by $\mathrm{Cr}(\mathrm{VI})\left(2.47 \times 10^{-6}\right)$ and As $\left(1.88 \times 10^{-6}\right)$. Thus, these three carcinogens presented the median $\mathrm{CR}_{i n h}$ above the acceptable risk level of $1 \times 10^{-6}$. For the $\mathrm{CR}_{i n h}$ estimates at the $95^{\text {th }}$ percentile, Ni still showed the highest cancer risk of $1.20 \times 10^{-5}$. In general, the $95^{\text {th }}$ percentile cumulative cancer risks obtained by summation risks of these three metals (including $\mathrm{Cr}$ (VI), Ni and As) are 25.4 per one million. Cancer risk estimates were similar for male and female adults (data not shown).

\section{Discussion}

Fine particle pollution is the leading factor influencing global air quality and public health. There are debates about whether fixed-site ambient $\mathrm{PM}_{2.5}$ monitoring is a good surrogate of personal exposure (Richmond-Bryant and Long 2020). Heterogeneity between ambient and personal exposure to heavy metal(loid)s (e.g., Mn, Cr, As) have been demonstrated in another publication (Chen et al. 2019a). Previous findings suggest performing repeated personal 
Table 6 Excess life cancer risk of particle-bound heavy metals in adult participants via inhalation

\begin{tabular}{llllllllllllll}
\hline & $\begin{array}{l}\text { Cr }(\mathrm{VI}) \\
\text { Mean }\end{array}$ & SD $^{\text {a }}$ & $5^{\text {th }}$ & $95^{\text {th }}$ & $\begin{array}{l}\text { Ni } \\
\text { Mean }\end{array}$ & & SD & $5^{\text {th }}$ & $95^{\text {th }}$ & As & SD & $5^{\text {th }}$ & $95^{\text {th }}$ \\
\hline Session 1 & $1.24 \mathrm{E}-06$ & $1.34 \mathrm{E}-06$ & $2.85 \mathrm{E}-07$ & $4.18 \mathrm{E}-06$ & $3.65 \mathrm{E}-07$ & $3.83 \mathrm{E}-07$ & $1.78 \mathrm{E}-08$ & $1.38 \mathrm{E}-06$ & $3.41 \mathrm{E}-06$ & $3.14 \mathrm{E}-06$ & $6.36 \mathrm{E}-07$ & $9.74 \mathrm{E}-06$ \\
Session 2 & $2.49 \mathrm{E}-06$ & $2.46 \mathrm{E}-06$ & $6.92 \mathrm{E}-07$ & $6.56 \mathrm{E}-06$ & $4.99 \mathrm{E}-07$ & $4.12 \mathrm{E}-07$ & $1.02 \mathrm{E}-07$ & $1.38 \mathrm{E}-06$ & $4.87 \mathrm{E}-06$ & $3.30 \mathrm{E}-06$ & $1.43 \mathrm{E}-06$ & $1.09 \mathrm{E}-05$ \\
Total & $1.91 \mathrm{E}-06$ & $2.11 \mathrm{E}-05$ & $2.85 \mathrm{E}-07$ & $5.94 \mathrm{E}-06$ & $4.44 \mathrm{E}-07$ & $4.05 \mathrm{E}-07$ & $4.09 \mathrm{E}-08$ & $1.38 \mathrm{E}-06$ & $4.07 \mathrm{E}-06$ & $3.29 \mathrm{E}-06$ & $6.36 \mathrm{E}-07$ & $1.02 \mathrm{E}-05$ \\
\hline
\end{tabular}

${ }^{a} \mathrm{SD}$ refers to standard deviation

$\mathrm{PM}_{2.5}$ monitoring to reduce attenuation bias in air pollution epidemiology (Johannesson et al. 2011). Similarly, Lei et al. (2020) emphasized the necessity of personal monitoring for accurate assessment of chemical component (e.g., metals) exposures. Given the importance and need for personal monitoring in urban areas with high population densities, the present study aimed to fill the research gap.

Limited studies have reported heavy metal exposures measured during the sampling of individual participants (Nerriere et al. 2007). Our results were generated by the repeated personal monitoring of adult subjects (characterized by different occupations in different age groups) for over 1 year in Hong Kong. Among the studied metals in personal $\mathrm{PM}_{2.5}$ (Chen et al. 2019b), relatively higher $\mathrm{Cr}$, Mn, $\mathrm{Ni}, \mathrm{Cu}, \mathrm{Zn}, \mathrm{As}$, and $\mathrm{Pb}$ were observed in winter than in summer. However, there were no significant occupational variations in $\mathrm{HMs}$ exposure, except $\mathrm{Ni}, \mathrm{V}$, and As in homemakers. The results also revealed higher $\mathrm{Mn}$ and $\mathrm{Zn}$ exposure in nonoffice workers (e.g., mainly consisting of outdoor workers and van drivers) than their counterparts (e.g., office workers) (Chen et al. 2018). In addition, higher metal concentrations were observed in the ambient air than in personal $\mathrm{PM}_{2.5}$, except for $\mathrm{Cr}$ (e.g., personal to ambient ratio $=1.97$; SD = 2.98) (Chen et al. 2019a). Personal $\mathrm{PM}_{2.5}$ exposure was performed for $24 \mathrm{~h}$, accounting for both ambient and nonambient pollutant exposures during the participants' daily life. These results indicated the impacts of environmental parameters (e.g., study region, season) and between-subject variance (e.g., variability in individuals) on personal exposure. Accordingly, different health effects may respond to the heterogeneity in exposures. For instance, Baccarelli et al. (2014) reported higher metal concentrations in personal exposure and lung function associations for taxi drivers in Beijing, China, and not for office workers.

$\mathrm{Cr}$ (VI) in $\mathrm{PM}_{2.5}$ was estimated as one-seventh of total $\mathrm{Cr}$ concentrations in the current study (U.S. EPA 2010). As showed in Table 3, the results revealed that the mean and $95^{\text {th }}$ percentile of $\mathrm{Cr}(\mathrm{VI})$ in personal $\mathrm{PM}_{2.5}(0.94-1.47 \mathrm{ng} /$ $\mathrm{m}^{3}$ ) were above the critical level in air recommended by the World Health Organization (WHO $=0.25 \mathrm{ng} / \mathrm{m}^{3}$, concentration refers to an excess lifetime cancer risk of $1 \times 10^{-6}$ ). The $95^{\text {th }}$ percentile of $\mathrm{Ni}$ and As in personal $\mathrm{PM}_{2.5}$ were $11.8 \mathrm{ng} / \mathrm{m}^{3}$ and $5.2 \mathrm{ng} / \mathrm{m}^{3}$ (Table 3), respectively, lower than the WHO estimated reference levels $\left(25 \mathrm{ng} / \mathrm{m}^{3}, 6.6 \mathrm{ng} / \mathrm{m}^{3}\right.$, respectively). Heavy metal(loid) exposures for participants in this study were lower than those reported in previous studies conducted indoors or from ambient air in other Chinese cities (e.g., Beijing, Nanjing, Hangzhou) (Hu et al. 2012; Huang et al. 2018).

Sources of HMs in personal $\mathrm{PM}_{2.5}$ were a combination of local emissions and regional pollution. Similar findings have been demonstrated in other personal exposure studies (Lei et al. 2020). Mueller et al. (2011) indicated that V and $\mathrm{Ni}$ were fuel oil combustion markers from power plants or marine vessel engines. Other studies stated the consistent contribution of shipping emissions to $\mathrm{PM}_{2.5}$ in the coastal region. For instance, Pandolfi et al. (2011) reported a V/ Ni ratio of 3.0 in ambient $\mathrm{PM}_{2.5}$ in the Bay Area of Algeciras, Spain. In the current study, the average V/Ni ratios in personal $\mathrm{PM}_{2.5}$ ranged between 2.9 and 3.5, suggesting a stable shipping emissions source that impacts Hong Kong residents. Some studies indicated that ambient monitoring at fixed sites could not capture non-tailpipe exhaust in personal exposure (Chen et al. 2018; Nerriere et al. 2007). For example, research conducted in four metropolitan areas in France demonstrated spatial heterogeneity of personal exposure to $\mathrm{Zn}, \mathrm{Cu}, \mathrm{V}$, and $\mathrm{Cr}$, and higher exposure levels ( $20-90 \%)$ were found in traffic proximity and the industrial sector compared to the background area (Nerriere et al. 2007). Our previous findings indicated the elevated levels of personal exposure to $\mathrm{Cr}$ and $\mathrm{Cu}$ could be attributable to commuter exposure in the MTR system in Hong Kong (Chen et al. 2020a). Further, indoor origins (e.g., cooking, cooking fuel) are potential sources of personal exposure to heavy metal(loid)s.

The reasons for health risk assessment are to support air pollution prevention, exposure mitigation, regulatory decision-making, and public health protection. Our study could objectively apportion the degree of cancer and non-cancer risks of HMs in personal $\mathrm{PM}_{2.5}$ exposures in adult participants. As noted, although $\mathrm{Zn}$ contributed to the most mass of HMs in personal $\mathrm{PM}_{2.5}, \mathrm{Cu}$ exhibited the highest HQ value. The $95^{\text {th }}$ percentile of HQ values for $\mathrm{Cu}$ was higher than one (2.0-3.0), revealing potential non-cancer risks. Furthermore, HI values (1.2-1.6) for the target HMs were larger than one, suggesting potential non-carcinogenic 

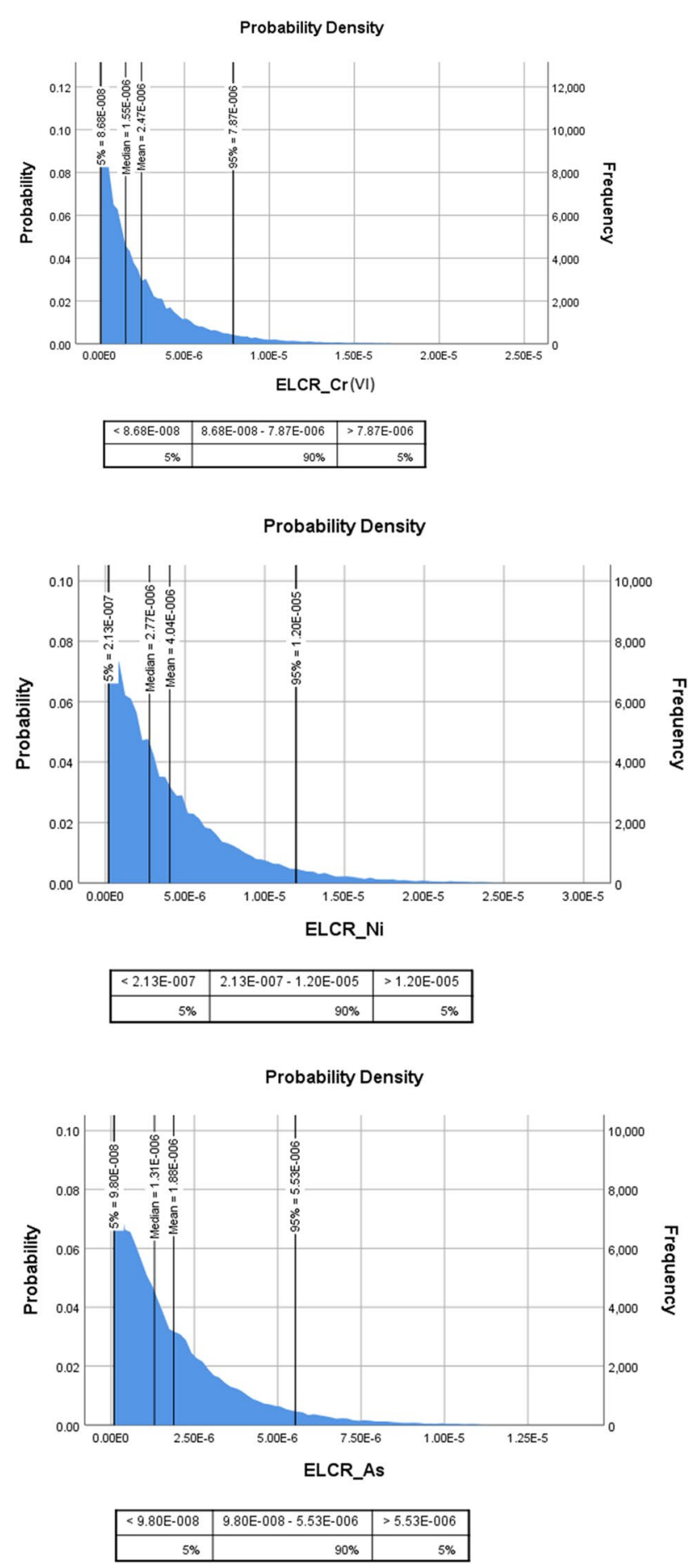

Fig. 3 Excess lifetime cancer risk (ELCR) for personal exposure to airborne metal(loid)s [Cr (VI), Ni, As] via inhalation

risks of HMs for the adult participants. These results suggest that the Hong Kong adult residents may face potential non-cancer risks from $\mathrm{Cu}$ and the cumulative effect of HMs via inhalation. Similar findings have also been reported in other Chinese megacities (e.g., Shanxi, Nanjing) (Table 7). This includes the Hu et al. (2012) study that indicated potential non-cancer health risk of HMs (HI $=2.9)\left(\mathrm{As}, \mathrm{Cd}, \mathrm{Co}\right.$, and $\mathrm{Ni}$ ) in $\mathrm{PM}_{2.5}$ via inhalation for adults in Nanjing, China.

Epidemiological and toxicological studies have demonstrated the adverse effects of exposure to HMs on human health (e.g., hospital admission, mortality). For instance, Tian et al. (2013) indicated that exposure to particles from shipping emissions (characterized by $\mathrm{Ni}$ and $\mathrm{V}$ ) were strongly associated with increased cardiovascular hospitalizations in Hong Kong. Also, Pun et al. (2014) reported strong associations between ambient $\mathrm{PM}_{2.5}$-bound heavy metals (e.g., $\mathrm{Mn}, \mathrm{Ni}$ ) and respiratory and cardiovascular hospitalizations in Hong Kong. Other studies have suggested that pollution levels, metal toxicity, and exposure behavior patterns (e.g., exposure duration) contributed to potential health risks of heavy metal exposure. A previous study conducted in the public transport systems in Hong Kong indicated in vitro personal $\mathrm{PM}_{2.5}$ bioreactivity was attributed to commuter exposure to $\mathrm{Mn}, \mathrm{Ni}, \mathrm{Zn}$, and $\mathrm{Co}$. A recent toxicological study revealed that $\mathrm{Cu}$ from vehicle brake systems exhibited toxic effects (e.g., ROS production, increased expression of pro-inflammation cytokine) on A549 cells (Figliuzzi et al. 2020). Consistent results about the negative impacts of personal exposure to heavy metals were demonstrated in other regions/countries. For example, $\mathrm{Wu}$ et al. (2013) found positive associations between $\mathrm{Zn}$, $\mathrm{Cu}, \mathrm{V}$, and $\mathrm{Pb}$ in ambient $\mathrm{PM}_{2.5}$ with lung function in young adults in Beijing, China. Madrigal et al. (2018) suggested that environmental exposure to $\mathrm{Mn}$ and $\mathrm{Pb}$ might adversely impact the pulmonary function of young adults in the USA.

Significantly higher exposure concentrations and chronic daily intake of $\mathrm{HMs}(\mathrm{Cr}, \mathrm{Ni}, \mathrm{Cu}, \mathrm{As})$ were reported for the study subjects participating in the one-year sampling program (i.e., session 2) (Tables 3 and S3). Minimal gender differences existed in exposure concentrations and chronic daily intake of heavy metals in male and female subjects (Table S4). In general, Cr (VI) $\left(5.09 \times 10^{-5}\right)$ and As $(1.22$ $\times 10^{-5}$ ) exhibited the highest cancer risks for these study participants in session 2 . These results might be attributed to repeated personal monitoring in different seasons that could capture the distinct variations in exposure concentrations of HMs, indicating that sustained long-term personal measurement is needed in urban areas. Cancer risks of heavy metal(loid)s in ambient $\mathrm{PM}_{2.5}$ have been estimated in different Chinese cities, and most studies have indicated that $\mathrm{Cr}$ (VI) in $\mathrm{PM}_{2.5}$ exhibited the highest cancer risks via inhalation for adults (Table 7). Further, Liu et al. (2018) reported that As from coal combustion posed the highest cancer risks to adults in Beijing, China. Another study investigated the health risks of source-specific heavy metals, suggesting traffic-related emissions and coal combustion were significant contributors to cancer and non-cancer risks for children and adults in Beijing, China (Huang et al. 2018). 


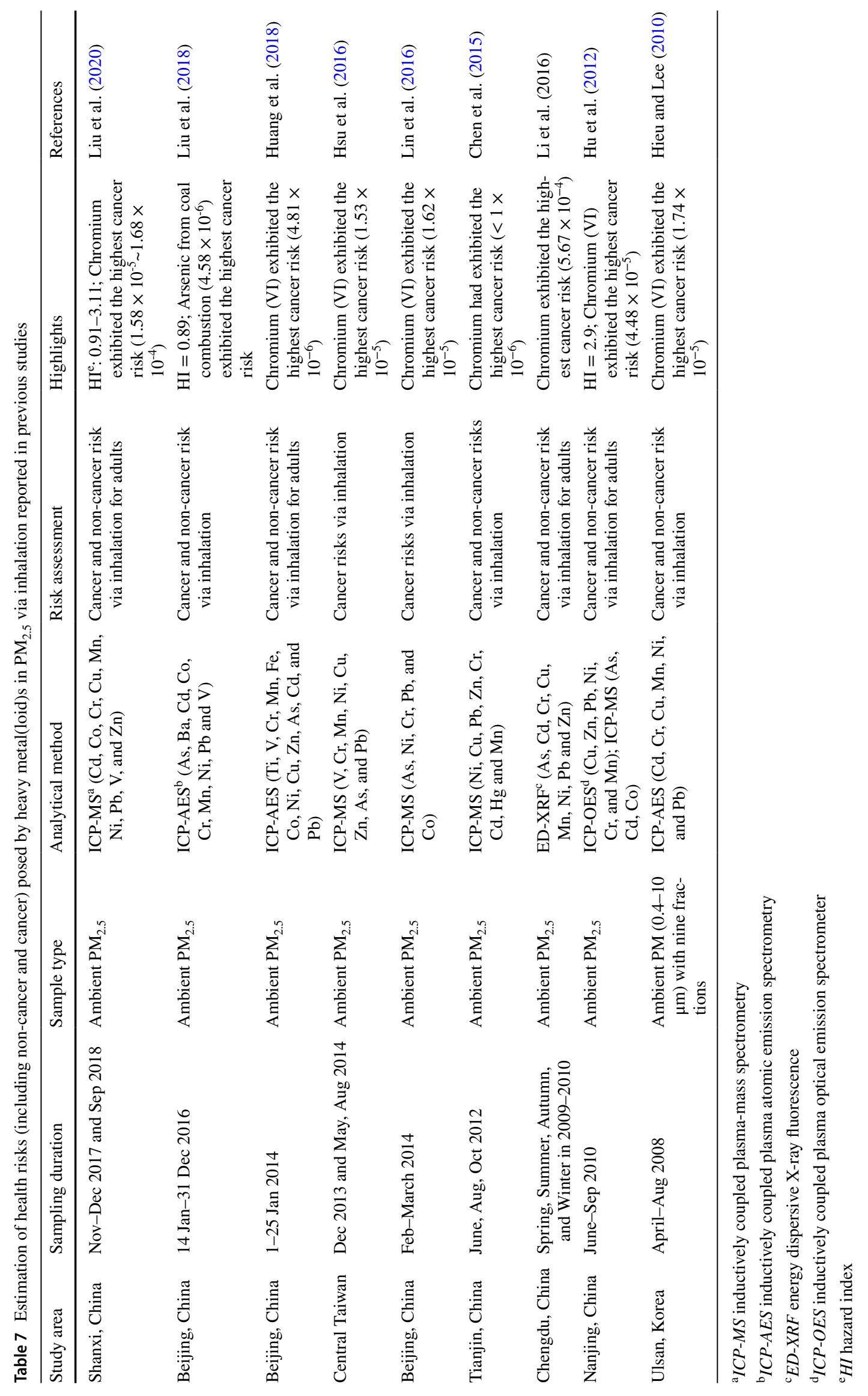


Excess lifetime cancer risks of $\mathrm{Cr}(\mathrm{VI}), \mathrm{Ni}$, and $\mathrm{As}$ via the inhalation route are attributable to IURs and exposure concentrations of the targeted heavy metal(loid)s in adult participants. The IUR values may also result in certain uncertainties in health risks assessment, which is the estimated risk of continuous lifetime exposure to an agent of 1 $\mu \mathrm{g} / \mathrm{m}^{3}$. RfC and IURs have accommodated age differences, as suggested in the Superfund Program (Part F) (U.S. EPA 2009). Presumably, the direct measured personal exposure reflect the possible health risks posed by heavy metal(loid)s for participants. These results indicated $\mathrm{Cr}(\mathrm{VI}), \mathrm{Ni}$, and $\mathrm{As}$ in personal $\mathrm{PM}_{2.5}$ posed non-negligible cancer risks for these adults in the study area and (or) their peers who shared very similar individual characteristics. Accordingly, the cumulative probability distribution of $\mathrm{CR}_{\text {inh }}$ for $\mathrm{Cr}(\mathrm{VI}), \mathrm{Ni}$, and As via inhalation was assessed using Monte Carlo simulation (Fig. 3). Consistent with the results derived from the study participants, $\mathrm{Cr}(\mathrm{VI}), \mathrm{Ni}$, and $\mathrm{As}$ had $95^{\text {th }} \mathrm{CR}_{i n h}$ that exceeded the negligible levels of one per one million.

The bioaccessibility of HMs is considered more accurate and reliable for health risk assessment. Huang et al. (2014) indicated that the inhalation bioaccessibilities of HMs (e.g., $\mathrm{Zn}, \mathrm{Mn}, \mathrm{Cu}, \mathrm{As}, \mathrm{Ni}, \mathrm{Pb}, \mathrm{Cr}$ ) in indoor $\mathrm{PM}_{2.5}$ in Guangzhou, China, ranged from 17.0 to $57.3 \%$. In the current study, we analyzed and reported the total metal concentrations in personal exposure. Yet, the combined effects of heavy metals are not clearly shown, and the health risks posed by bioaccessible and bioavailable HMs via inhalation may be overestimated in this case. Previous findings also indicated significant variation in health risks of HMs via different exposure routes (Huang et al. 2014), and more significant health risks were reported in children than adults. For example, Zhang et al. (2015) investigated the health risks of $\mathrm{HMs}$ in $\mathrm{PM}_{2.5}$ exposure in children, revealing that children had higher risks posed by HMs than adults due to more frequent hand-tomouth activities. Further studies are needed to better explore the variations in health risks via inhalation from various sub-populations (e.g., children, adolescents).

In assessing health risks, some limitations should be considered. A few months (e.g., applied on specific days) to a year-long measurement may not represent exposure concentrations covering the adult life span. Therefore, these results about health risks are indicative and should be interpreted with caution. Our study had the advantage of direct personal monitoring from individual adult participants under real environmental conditions versus other typical studies that applied ambient monitoring or estimated personal exposures by combining indoor and outdoor exposure. This study provides an exposure scenario from a scientific perspective and a preliminary investigation of contamination levels and detrimental health risks of heavy metals in personal exposure for adult residents of Hong Kong. Further, these results are critical for the corresponding evidence-based policymaking to control emissions from vehicles and marine vessels in Hong Kong from a regulatory perspective. Despite the uncertainty inherent in cancer risk assessment in this study, our results serve as useful indices for future health risk assessment studies in China's high-density Greater Bay Area (GBA).

\section{Conclusions}

This study explored the characteristics of individual exposure to $\mathrm{HMs}$ in $\mathrm{PM}_{2.5}$ and the corresponding health risks posed by the targeted HMs via inhalation in adult residents of Hong Kong. Exposure concentrations for HMs were considerably higher than those reported in other developed countries and lower than those in Chinese cities. The principal component analyses revealed three sources: regional pollution, traffic-related pollution, and shipping emission that contributed to HMs in personal $\mathrm{PM}_{2.5}$. The HI values for HMs were greater than 1 , indicating that the targeted metals might pose non-cancer risks to adults in Hong Kong. The inhalation cancer risks (mean and $95^{\text {th }}$ percentile $\mathrm{CR}_{\text {inh }}$ values) associated with personal exposure to $\mathrm{Ni}, \mathrm{Cr}(\mathrm{VI})$, and As exceeded the U.S. EPA benchmark of $1 \times 10^{-6}$. Our study highlights the need to conduct long-term personal monitoring for accurate health risk assessment, guiding the implementation of effective mitigation strategies towards cleaner air in Hong Kong and GBA, China.

Supplementary Information The online version contains supplementary material available at https://doi.org/10.1007/s11869-021-01115-6.

Acknowledgements We are thankful to Prof. Mingjuan Huang from Sun Yat-sen University and Dr. Zhiyuan Li from The Chinese University of Hong Kong for the technical guidance regarding the Monte Carlo simulation.

Author contribution X-CC: conceptualization, formal analysis, investigation, methodology, project administration, visualization, writingoriginal draft, writing-review and editing, and funding acquisition. TJW: methodology, resources, validation, writing-review and editing. CS: software, resources, writing-review and editing. K-FH: data curation, methodology, investigation, validation, writing-review and editing, funding acquisition. CW: resources, writing-review and editing.

Funding Xiao-Cui Chen acknowledges the Young Scientists Fund of the National Natural Science Foundation of China (Grant No. 4197181). This study was supported by grant from the Research Grant Council of the Hong Kong Special Administrative Region China, General Research Fund (Project No. CUHK 14203719).

Data availability statement Data will be made available on reasonable request.

\section{Declarations}

Conflicts of interest The authors declare no conflict of interset. 
Open Access This article is licensed under a Creative Commons Attribution 4.0 International License, which permits use, sharing, adaptation, distribution and reproduction in any medium or format, as long as you give appropriate credit to the original author(s) and the source, provide a link to the Creative Commons licence, and indicate if changes were made. The images or other third party material in this article are included in the article's Creative Commons licence, unless indicated otherwise in a credit line to the material. If material is not included in the article's Creative Commons licence and your intended use is not permitted by statutory regulation or exceeds the permitted use, you will need to obtain permission directly from the copyright holder. To view a copy of this licence, visit http://creativecommons.org/licenses/by/4.0/.

\section{References}

Baccarelli AA, Zheng Y, Zhang X, Chang D, Liu L, Wolf KR et al (2014) Air pollution exposure and lung function in highly exposed subjects in Beijing, China: a repeated-measure study. Part Fibre Toxicol 11(1):51

CalEPA (California Environmental Protection Agency) (1997) Technical support document for the determination of noncancer chronic reference exposure levels. Draft for public review. Office of Environmental Health Hazard Assessment, Air Toxicology and Epidemiology Section, Berkeley, CA. https://archive.epa.gov/epawa ste/hazard/web/pdf/section7-10.pdf

California Environmental Protection Agency (CalEPA) (2008) Technical support document for the determination of noncancer chronic reference exposure levels. Office of Environmental Health Hazard Assessment, Berkeley, CA. (updated July 2014). https://oehha.ca. gov/media/downloads/crnr/appendixd1final.pdf

Cao S, Duan X, Zhao X, Chen Y, Wang B, Sun C et al (2016) Health risks of children's cumulative and aggregative exposure to metals and metalloids in a typical urban environment in China. Chemosphere 147:404-411

Chen P, Bi X, Zhang J, Wu J, Feng Y (2015) Assessment of heavy metal pollution characteristics and human health risk of exposure to ambient PM2. 5 in Tianjin, China. Particuology 20:104-109

Chen XC, Ward TJ, Cao JJ, Lee SC, Chow JC, Lau GNC et al (2018) Determinants of personal exposure to fine particulate matter (PM2.5) in adult subjects in Hong Kong. Sci Total Environ 628-629:1165-1177

Chen XC, Chow JC, Ward TJ, Cao JJ, Lee SC, Watson JG et al (2019a) Estimation of personal exposure to fine particles (PM2.5) of ambient origin for healthy adults in Hong Kong. Sci Total Environ 654:514-524

Chen XC, Ward TJ, Cao JJ, Lee SC, Lau NC, Yim SHL et al (2019b) Source identification of personal exposure to fine particulate matter (PM2.5) among adult residents of Hong Kong. Atmos Environ 218:116999

Chen XC, Cao JJ, Ward TJ, Tian LW, Ning Z, Gali NK et al (2020a) Characteristics and toxicological effects of commuter exposure to black carbon and metal components of fine particles (PM2.5) in Hong Kong. Sci Total Environ 742:140501

Chen XC, Chuang HC, Ward TJ, Tian L, Cao JJ, Ho SS et al (2020b) Indoor, outdoor, and personal exposure to PM2.5 and their bioreactivity among healthy residents of Hong Kong. Environ Res 188:109780

Chen XC, Chuang HC, Ward TJ, Sarkar C, Webster C, Cao J et al (2021) Toxicological effects of personal exposure to fine particles in adult residents of Hong Kong. Environ Pollut 275:116633

Chow JC, Watson J (2012) Chemical analyses of particle filter deposits. Aerosols Handb: Measurement, Dosimetry, and Health Effects 2:177-202
Duan JC, Tan JH (2013) Atmospheric heavy metals and Arsenic in China: Situation, sources and control policies. Atmos Environ 74:93-101

Fan ZL, Pun VC, Chen XC, Hong Q, Tian LW, Ho SSH et al (2018) Personal exposure to fine particles (PM 2.5) and respiratory inflammation of common residents in Hong Kong. Environ Res 164:24-31

Figliuzzi M, Tironi M, Longaretti L, Mancini A, Teoldi F, Sangalli F et al (2020) Copper-dependent biological effects of particulate matter produced by brake systems on lung alveolar cells. Arch Toxicol 94(9):2965-2979

Goldhaber SB (2003) Trace element risk assessment: essentiality vs. toxicity. Regul Toxicol Pharmacol 38(2):232-242

Han B, You Y, Liu Y, Xu J, Zhou J, Zhang J et al (2019) Inhalation cancer risk estimation of source-specific personal exposure for particulate matter-bound polycyclic aromatic hydrocarbons based on positive matrix factorization. Environ Sci Pollut Res Int 26(10): 10230-10239

Hieu NT, Lee BK (2010) Characteristics of particulate matter and metals in the ambient air from a residential area in the largest industrial city in Korea. Atmos Res 98(2-4):526-537

Hong Kong Census and Statistics Department (2016) Hong Kong 2016 Population By census. Hong Kong Government of Special Administrative Region (HKSAR): Census and Statistics Department Hong Kong. https://www.bycensus2016.gov.hk/data/16bcsummary-results.pdf. Accessed Feb 2017

Hu X, Zhang Y, Ding ZH, Wang TJ, Lian HZ, Sun YY et al (2012) Bioaccessibility and health risk of arsenic and heavy metals $(\mathrm{Cd}$, $\mathrm{Co}, \mathrm{Cr}, \mathrm{Cu}, \mathrm{Ni}, \mathrm{Pb}, \mathrm{Zn}$ and $\mathrm{Mn}$ ) in TSP and PM2.5 in Nanjing, China. Atmos Environ 57:146-152

Hsu C-Y, Chiang H-C, Lin S-L, Chen M-J, Lin T-Y, Chen Y-C (2016) Elemental characterization and source apportionment of PM10 and PM2. 5 in the western coastal area of central Taiwan. Sci Total Environ 541:1139-1150

Huang M, Wang W, Chan CY, Cheung KC, Man YB, Wang X et al (2014) Contamination and risk assessment (based on bioaccessibility via ingestion and inhalation) of metal(loid)s in outdoor and indoor particles from urban centers of Guangzhou, China. Sci Total Environ 479-480:117-124

Huang RJ, Cheng R, Jing M, Yang L, Li Y, Chen Q et al (2018) Sourcespecific health risk analysis on particulate trace elements: coal combustion and traffic emission as major contributors in Wintertime Beijing. Environ Sci Technol 52(19):10967-10974

IARC (2012) Agents classified by the IARC Monographs, volumes 1-108, 2012. Available online: http://monographs.iarc.fr/ENG/ Classification/index.php. Accessed 20 July 2015

Jahn HJ, Kraemer A, Chen XC, Chan CY, Engling G, Ward TJ (2013) Ambient and personal PM2.5 exposure assessment in the Chinese megacity of Guangzhou. Atmos Environ 74:402-411

Jiang SYN, Yang FH, Chan KL, Ning Z (2014) Water solubility of metals in coarse PM and PM2.5 in typical urban environment in Hong Kong. Atmos Pollut Res 5(2):236-244

Johannesson S, Rappaport SM, Sallsten G (2011) Variability of environmental exposure to fine particles, black smoke, and trace elements among a Swedish population. J Expo Sci Environ Epidemiol 21(5):506-514

Johansson C, Norman M, Burman L (2009) Road traffic emission factors for heavy metals. Atmos Environ 43(31):4681-4688

Lau WK, Liang P, Man YB, Chung SS, Wong MH (2014) Human health risk assessment based on trace metals in suspended air particulates, surface dust, and floor dust from e-waste recycling workshops in Hong Kong, China. Environ Sci Pollut Res Int 21(5):3813-3825

Lei X, Chen R, Wang C, Shi J, Zhao Z, Li W et al (2020) Necessity of personal sampling for exposure assessment on specific 
constituents of PM2.5: results of a panel study in Shanghai, China. Environ Int 141:105786

Lin Y-C, Hsu S-C, Chou CC-K, Zhang R, Wu Y, Kao S-J et al (2016) Wintertime haze deterioration in Beijing by industrial pollution deduced from trace metal fingerprints and enhanced health risk by heavy metals. Environ Pollut 208:284-293

Liu J, Chen Y, Chao S, Cao H, Zhang A, Yang Y (2018) Emission control priority of PM2.5-bound heavy metals in different seasons: a comprehensive analysis from health risk perspective. Sci Total Environ 644:20-30

Liu ZY, Zhou JZ, Zhang J, Mao YB, Huang X, Qian GR (2020) Evaluation for the heavy metal risk in fine particulate matter from the perspective of urban energy and industrial structure in China: A meta-analysis. J Clean Prod 244:118597

Luo XS, Yu S, Li XD (2011) Distribution, availability, and sources of trace metals in different particle size fractions of urban soils in Hong Kong: implications for assessing the risk to human health. Environ Pollut 159(5):1317-1326

Madrigal JM, Persky V, Pappalardo A, Argos M (2018) Association of heavy metals with measures of pulmonary function in children and youth: results from the National Health and Nutrition Examination Survey (NHANES). Environ Int 121(Pt 1):871-878

Man YB, Sun XL, Zhao YG, Lopez BN, Chung SS, Wu SC et al (2010) Health risk assessment of abandoned agricultural soils based on heavy metal contents in Hong Kong, the world's most populated city. Environ Int 36(6):570-576

Mao X, Hu X, Wang Y, Xia W, Zhao S, Wan Y (2020) Temporal trend of arsenic in outdoor air PM2.5 in Wuhan, China, in 2015-2017 and the personal inhalation of PM-bound arsenic: implications for human exposure. Environ Sci Pollut Res Int 27(17):21654-21665

Morawska L, Afshari A, Bae GN, Buonanno G, Chao CY, Hanninen $\mathrm{O}$ et al (2013) Indoor aerosols: from personal exposure to risk assessment. Indoor Air 23(6):462-487

Mueller D, Uibel S, Takemura M, Klingelhoefer D, Groneberg DA (2011) Ships, ports and particulate air pollution - an analysis of recent studies. J Occup Med Toxicol 6(1):31

Nerriere E, Guegan H, Bordigoni B, Hautemaniere A, Momas I, Ladner J et al (2007) Spatial heterogeneity of personal exposure to airborne metals in French urban areas. Sci Total Environ 373(1):49-56

OEHHA (California Office of Environmental Health Hazard Assessment) (2009) Air toxics hot spots program technical support document for non-cancer reference exposure level (REL). Permissible Exposure limits for Chemical Contaminants. https://www.lawa. org/-/media/mscnorth/4_3_msc_deir_human_health_risk_asses sment.ashx

Pandolfi M, Gonzalez-Castanedo Y, Alastuey A, Jesus D, Mantilla E, De La Campa AS et al (2011) Source apportionment of PM 10 and PM 2.5 at multiple sites in the strait of Gibraltar by PMF: impact of shipping emissions. Environ Sci Pollut Res 18(2):260-269

Phillips L, Moya J (2013) The evolution of EPA's exposure factors handbook and its future as an exposure assessment resource. $J$ Exp Sci Environ Epidemiol 23(1):13-21

Pun VC, Yu IT, Qiu H, Ho KF, Sun Z, Louie PK et al (2014) Shortterm associations of cause-specific emergency hospitalizations and particulate matter chemical components in Hong Kong. Am J Epidemiol 179(9):1086-1095

Richmond-Bryant J, Long TC (2020) Influence of exposure measurement errors on results from epidemiologic studies of different designs. J Expo Sci Environ Epidemiol 30(3):420-429
Shi T, Wang Y (2020) Heavy metals in indoor dust: Spatial distribution, influencing factors, and potential health risks. Sci Total Environ 755(Pt 1):142367

Shi GT, Chen ZL, Bi CJ, Wang L, Teng JY, Li YS et al (2011) A comparative study of health risk of potentially toxic metals in urban and suburban road dust in the most populated city of China. Atmos Environ 45(3):764-771

Silvera SAN, Rohan TE (2007) Trace elements and cancer risk: a review of the epidemiologic evidence. Cancer Causes Control 18(1):7-27

Tian LW, Ho KF, Louie PKK, Qiu H, Pun VC, Kan HD et al (2013) Shipping emissions associated with increased cardiovascular hospitalizations. Atmos Environ 74:320-325

U.S. Environmental Protection Agency (2011) Exposure factors handbook 2011 edition (Final). US Environmental Protection Agency Washington, Washingto

U.S. EPA (2007) IRIS, Integrated Risk Information System, 2007. Available online: https://cfpub.epa.gov/ncea/iris_drafts/atoz.cfm? list_type $=$ alpha. Accessed 19 Jan 2008

U.S. EPA (2009) Risk Assessment Guidance for Superfund (RAGS), Volume I: Human Health Evaluation Manual (Part F, Supplemental Guidance for Inhalation Risk Assessment): Final. US Environmental Protection Agency, Washington

U.S. EPA (2010) IRIS Toxicological Review of Hexavalent Chromium (2010 External Review Draft). US Environmental Protection Agency, Washington EPA/635/R-10/004A, 2010

Wang Z, Duan X, Liu P, Nie J, Huang N, Zhang J (2009) Human exposure factors of Chinese people in environmental health risk assessment. Res Environ Sci 22(10):1164-1175

Weis BK, Balshaw D, Barr JR, Brown D, Ellisman M, Lioy P et al (2005) Personalized exposure assessment: promising approaches for human environmental health research. Environ Health Perspect 113(7):840-848

Wong CM, Lai HK, Tsang H, Thach TQ, Thomas GN, Lam KB et al (2015) Satellite-based estimates of long-term exposure to fine particles and association with mortality in elderly Hong Kong residents. Environ Health Perspect 123(11):1167-1172

Wong A, Lou W, Ho KF, Yiu BK, Lin S, Chu WC et al (2020) Indoor incense burning impacts cognitive functions and brain functional connectivity in community older adults. Sci Rep 10(1):7090

Wu S, Deng F, Wang X, Wei H, Shima M, Huang J et al (2013) Association of lung function in a panel of young healthy adults with various chemical components of ambient fine particulate air pollution in Beijing, China. Atmos Environ 77:873-884

Zhang N, Han B, He F, Xu J, Niu C, Zhou J et al (2015) Characterization, health risk of heavy metals, and source apportionment of atmospheric PM2.5 to children in summer and winter: an exposure panel study in Tianjin, China. Air Qual Atmos Health 8(4):347-357

Zhou J, You Y, Bai Z, Hu Y, Zhang J, Zhang N (2011) Health risk assessment of personal inhalation exposure to volatile organic compounds in Tianjin, China. Sci Total Environ 409(3):452-459

Publisher's note Springer Nature remains neutral with regard to jurisdictional claims in published maps and institutional affiliations. 